\title{
Effect of a carbohydrate rich diet in vas deferens contractility in rats
}

\author{
Ekrem Akdeniz $^{1^{*}}$, Suleyman Sirri Bilge ${ }^{2}$, Mustafa Suat Bolat ${ }^{1}$, Fatih Firat ${ }^{3}$, Arzu Erdal Agri ${ }^{2}$, \\ Omer Alici ${ }^{4}$, Onder Cinar ${ }^{1}$, Fikret Erdemir ${ }^{5}$
}

\begin{abstract}
Objective: We aimed to investigate the effects of a Carbohydrate-rich diet on vas deferens contractility and histology.

Methods and Patients: Twenty mature male rats were subjected into two groups. The control group received regular food and water and the study group received regular food and a carbohydrate-rich liquid diet mixture of $37-40 \%$ fructose, $30-36 \%$ sucrose and $27-30 \%$ glucose instead of water and prepared stock diet was diluted with 50\% water. Animals were weighted and sacrificed after six weeks and the vas deferens has been evaluated with in vitro studies. Five rats from both the control and study groups, were separated into subgroups for dapoxetine administration 4 hours before they were sacrificed
\end{abstract}

Results: At the beginning of this study, the mean body weights were $228.6 \pm 6.7 \mathrm{~g}$ (range: $205-237$ ) and $231.4 \pm 9.6 \mathrm{~g}$ (range: $202-243$ ) in control and study groups, respectively. The mean body weights were $247.1 \pm 4.8$ $\mathrm{g}(236-252)$ in the control group and $318.8 \pm 9.3 \mathrm{~g}(314-326)$ in the study group $(\mathrm{p}<0.001)$. Weight gain was more distinct in the study group when compared to control group $(\mathrm{p}<0.001)(9 \%$ vs $27.4 \%)$. Contractile responses were recorded in each group, including the dapoxetine subgroups, to various noradrenaline concentrations; all groups had similar results ( $>00.05$ ). Responses to Adenosine Three Phosphate (ATP) were also not significant $(p>0.05)$. The contractile responses at the same frequencies of electrical field stimulation (EFS) were similar in both groups $(\mathrm{p}>0.05)$. Histological examinations showed no abnormalities in either group. .

Conclusion: Carbohydrate-rich diet caused no increase in fibrotic activity, and pharmacological and histological properties remained stable, but caused significant weight gain over a short time period. Furthermore, dapoxetine had no effect on the contractility of the vas deferens

Key Words: Dapoxetine, Carbohydrate, Obesity, Vas deferens

\section{Introduction}

The ejaculation process requires coordinated inputs from both the central and peripheral nervous systems to produce the expulsion of semen from the urethra. Three distinct phases of semen transportation have been defined: emission, closure of the bladder neck and ejaculation. Potentialization of the cerebral cortex stimulates the prostatic smooth muscle, seminal vesicles and the vas deferens via sympathetic nerves in the thoracolumbar axis. Thus, the deposition of preejaculatory fluid into the posterior urethra (emission phase) facilitates. Sympathetic innervation initiates the bladder neck closure and finally, the propelling of semen occurs. There are many reasons why this delicate mechanism may be easily affected.
Obesity is defined as abnormal or excessive fat accumulation that increases health risks. By 2030, almost half of the population will be clinically overweight or obese (1). Obesity threatens the public health on a worldwide scale and is associated with gastrointestinal, cardiovascular, neuromuscular, genitourinary and oncological diseases, which may cause high morbidity and mortality (2).

Obesity may occur for various reasons that include excessive intake of fatty foods, gallbladder disease, hypercholesterolemia, atherosclerosis, heart disease, hypertension, stroke, depression, sleep apnoea syndrome, urinary infections, lumbar postural disorders and neurological, metabolic and endocrinologic diseases.

Received 04-05-2016 Accepted 11-06-2016 Available Online 15-06-2016

1 Samsun Training and Research Hospital, Department of Urology, Samsun, Turkey

2 Ondokuz Mayis University, Department of Pharmacology, Samsun, Turkey

3 Tokat State Hospital, Urology Clinic, Tokat, Turkey

4 Gazi Osman Pasa University, Department of Pathology, Tokat, Turkey

5 Gazi Osman Pasa University, Department of Urology, Tokat, Turkey

*Corrospending Author: Ekrem Akdeniz E-mail: ekremakdeniz@yahoo.com Phone: 0903623111500 
Ejaculatory function may be affected by a variety of reasons with a commonly reported pathology being premature ejaculation (PE). Even though $\mathrm{PE}$ is not a life-threatening disturbance, it frequently causes lower satisfaction in sexual relationship, difficulty in relaxing during intercourse and less frequent intercourse (3). The prevalence of PE is $4-39 \%$ (4). Drugs used for lower urinary tract symptoms (LUTS), such as alpha blockers, may cause ejaculatory dysfunction (5). Hormonal disorders (hypo-or hyperthyroidism, diabetes mellitus, and hypogonadism), genital infectious diseases and psychiatric disturbances may also play a role in ejaculatory disturbances (6). Anejaculation is a another condition that involves the complete absence of ejaculation and may result from several causes including androgen deficiency, sympathetic denervation, pharmacologic agents and bladder neck/prostatic surgery.

The role of obesity in sexual function has gained importance in recent years. Not only high fat diets but also high amounts of carbohydrate consumption may have a negative effect on sexuality. Although obesity is considered as cause of PE, there is no strong evidence based on prospective studies in the literature (7). Sexual dysfunction, particularly PE may have related with smooth muscle contraction of vas deferens. While ACh (Acetylcholine) is responsible from stabile smooth muscle contraction, ACh and ATP both initiate nerve-mediated over-active smooth muscle contractions (8). These neurotransmitters rapidly break downs by $\mathrm{ACh}$ esterase. When $\mathrm{ACh}$ esterase activity reduces, purinergic component may be predominated and this may cause abnormal contractions. We used ATP and NA stimulation tests in order to show the contractile strength of vas deferens in the groups (9). Similarly, total contractile strength was measured using EFS, which represent the release of all neurotransmitters into the neuromuscular synaptic space (10).

In this present study, we aimed to investigate the effects of a Carbohydrate-rich diet on vas deferens contractility and histology in rats..

\section{Material and Methods}

Twenty mature male Sprague-Dawley rats 9-12 weeks of age were obtained from the Gazi Osman Paşa University vivarium sources. All procedures and protocols were conducted in accordance with the Guidelines for the Care and Use of Laboratory Animals (NIH application 865-23, Bethesda, MD, USA). Experiments were approved by the Gazi Osman Paşa University, Animal Care and Use Committee.

Rats were housed in a temperature and humiditycontrolled room $\left(22{ }^{\circ} \mathrm{C}\right.$ and $60 \pm 5 \%$, respectively) with a 12-hour light/dark cycle and were randomized into 2 groups of 10 animals each. The control group rats received regular food and water ad libitum. The study group rats received regular food and a liquid mixture of $37-40 \%$ fructose, $30-36 \%$ sucrose and $27-30 \%$ glucose instead of water, and stock nutrition was diluted with $50 \%$ water for feeding. At the beginning of this study, the mean body weights were $228.6 \pm 6.7 \mathrm{~g}$ (range: 205-237) and 231.4 $\pm 9.6 \mathrm{~g}$ (range: 202-243) in control and study groups, respectively. The mean body weights were $247.1 \pm 4.8 \mathrm{~g}(236-252)$ in the control group and $318.8 \pm 9.3 \mathrm{~g}$ (314-326) in the study group at the end of this study $(\mathrm{p}<0.001)$. Weight gain was higher in the study group than control group $(9 \%$ vs $27.4 \%$ ). After six weeks, rats were sacrificed for in vitro studies. Dapoxetine were administered to five rats from the control and study groups, 4 hours before scarification.

\section{In Vitro Experiments}

The vas deferens was prepared in $10 \mathrm{~mm}$ strips and transferred into organ baths containing $10 \mathrm{ml} \mathrm{Krebs}$ Henseleit solution (composition in $\mathrm{mM}$ : $\mathrm{NaCl}$ : 118, $\mathrm{KCl}:$ 5.6, $\mathrm{CaCl} 2: 2.5, \mathrm{MgSO} 4: 1.2, \mathrm{KH} 2 \mathrm{PO} 4: 0.9$, NaHCO3: 25, and glucose: 11). The solution was kept in the standard conditions $\left(5 \% \mathrm{CO} 2,37.2{ }^{\circ} \mathrm{C}\right.$ and $\mathrm{pH}$ 7.4). Each preparation was treated through a ring electrode (3 $\mathrm{mm}$ internal diameter, $1 \mathrm{~cm}$ apart) (MLA0305/8, AD Instruments, UK) connected to a stimulator (Grass, USA). The lower end of the preparation was attached to a holder, and the other end was attached to an isometric force transducer (MLT0201, AD Instruments, UK) coupled to a QuadBridge amplifier (ML118, AD Instruments, UK) that was connected to a digital recorder PowerLab/4SP (AD Instruments, UK). Strips were allowed to equilibrate for 1 hour followed by the application of 1 $\mathrm{g}$ of tension. The Krebs solution was refreshed every 15 minutes. The functional viability of the preparation was assessed by the addition of acetylcholine (Ach) and noradrenaline (NA) for vas deferens

\section{Vas deferens contractions}

NA (Sigma, USA) (10-8-10-5 M) and adenosine triphosphate (ATP) (Sigma, USA) (10 7-10- $4 \mathrm{M}$ ) were administered in a cumulative manner. The frequency-response curves were constructed as follows: square wave pulses $(60 \mathrm{~V}, 0.5 \mathrm{~ms})$ were delivered for 20 seconds at increasing frequencies (2$64 \mathrm{~Hz})$.

\section{Statistical Analysis}

All data are expressed as the mean \pm SEM. Data analyses were performed using GraphPad Instat software (v 3.0) (GraphPad, USA).

Following the assurance of a normal distribution of data, a one-way analysis of variance (ANOVA) with Tukey-Kramer post hoc tests were used for multiple comparisons. Values of $\mathrm{p}<0.05$ were regarded as statistically significant 


\section{Results}

Body weights were recorded after 6 weeks and the mean body weight was $247.1 \pm 4.8 \mathrm{~g}$ in the control group and $318.8 \pm 9.3 \mathrm{~g}$ in the study group $(27.4 \%$ increase). At the beginning of this study, the mean body weights were $228.6 \pm 6.7 \mathrm{~g}$ (range: $205-237$ ) and 231.4 $\pm 9.6 \mathrm{~g}$ (range: 202-243) in control and study groups, respectively. After six weeks the mean body weights were $247.1 \pm 4.8 \mathrm{~g}(236-252)$ in the control group and $318.8 \pm 9.3 \mathrm{~g} \mathrm{(314-326)}$ in the study group at the end of this study $(\mathrm{p}<0.001)$.
Pre-treatment with dapoxetine did not change the NAinduced vas deferens contractions in either group (Fig.1). The cumulative addition of ATP (10-7-10-4) elicited rapid, transient, concentration dependent contractions in both groups. However, no significant differences were seen between the control and study groups $(p>0.05)$. The addition of dapoxetine did not change the ATP-induced vas deferens contractions in either group ( $p>0.05)$ (Fig.2).

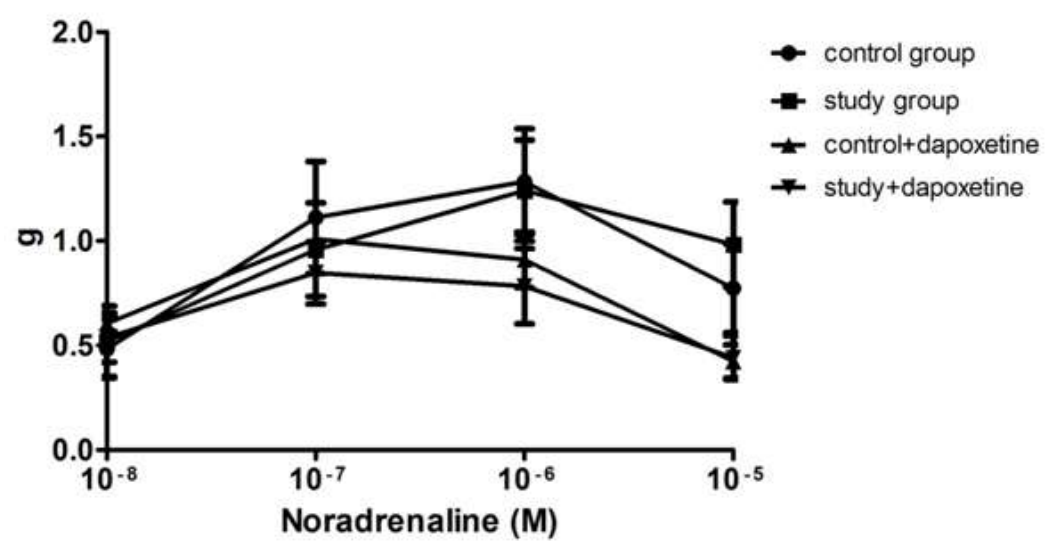

Figure 1: Contractions induced by Noradrenaline $\left(10^{-8}-10^{-5} \mathrm{M}\right)$ in vas deferens. Values have shown as the means \pm SE.

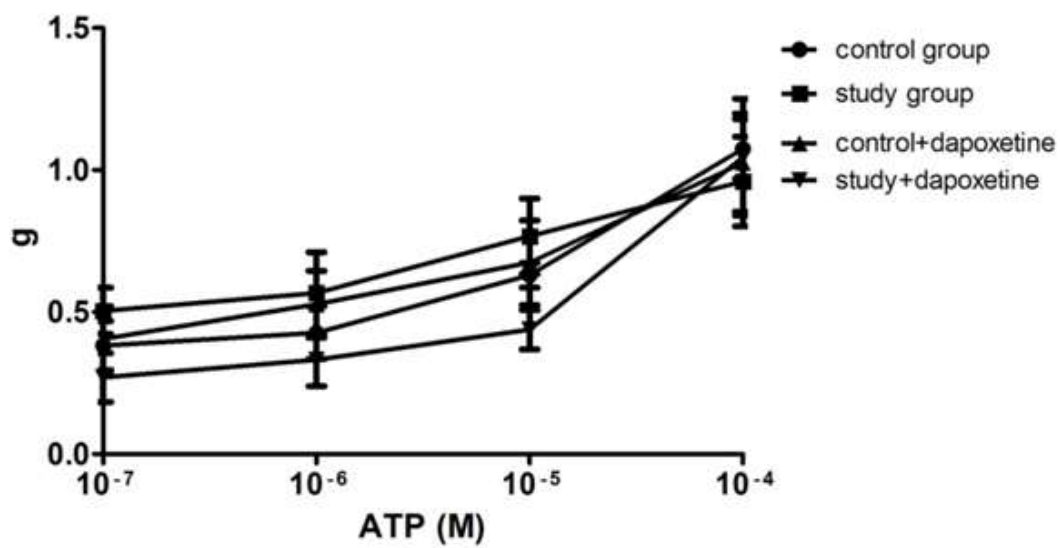

Figure 2: Contractions induced by ATP $\left(10^{-7}-10^{-4} \mathrm{M}\right)$ in vas deferens.

Values have shown as the means \pm SE.

The cumulative addition of NA (10-8-10-5M) induced repetitive phasic, concentration-dependent contractions in the vas deferens of both the control and study groups. There were no significant differences between the control and study groups $(\mathrm{p}>0.05)$.
Electrical stimulation of the vas deferens strips of the normal fed rats were recorded in frequencies of 2-64 $\mathrm{Hz}$. The contractile responses at the same frequencies of electrical field stimulation (EFS) were similar in both groups $(\mathrm{p}>0.05)$. 
Pretreatment with dapoxetine did not change the EFS induced vas deferens contractions in either group ( $p>0.05)$ (Fig.3). Histological examinations showed no abnormalities in the control group with hematoxylin and eosin $(\mathrm{H} \& \mathrm{E})$, and Masson's trichrome stain revealed no increase in subepithelial and intercellular fibrotic activity (Pic.1a and $b$, respectively). A carbohydrate-rich diet showed no increase in fibrotic activity in vas deferens (Pic.1c and d).

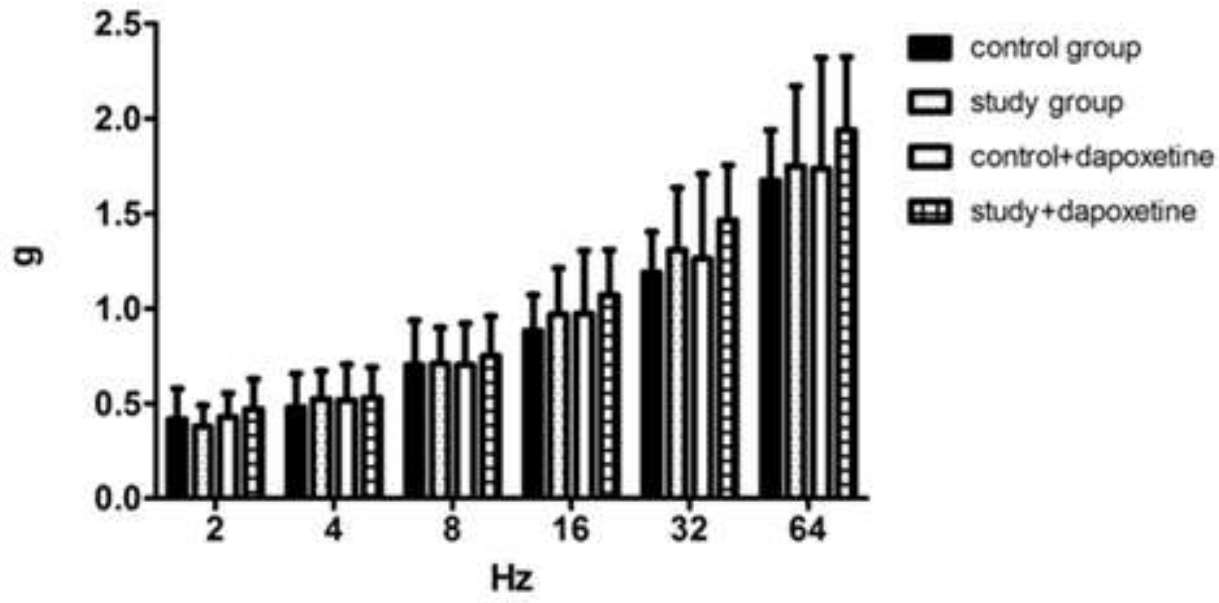

Figure 3: Contractions induced by EFS $(60 \mathrm{~V}, 0,5 \mathrm{~ms}, 2-64 \mathrm{~Hz})$ in vas deferens.

Values have shown as the means $\pm \mathrm{SE}$.
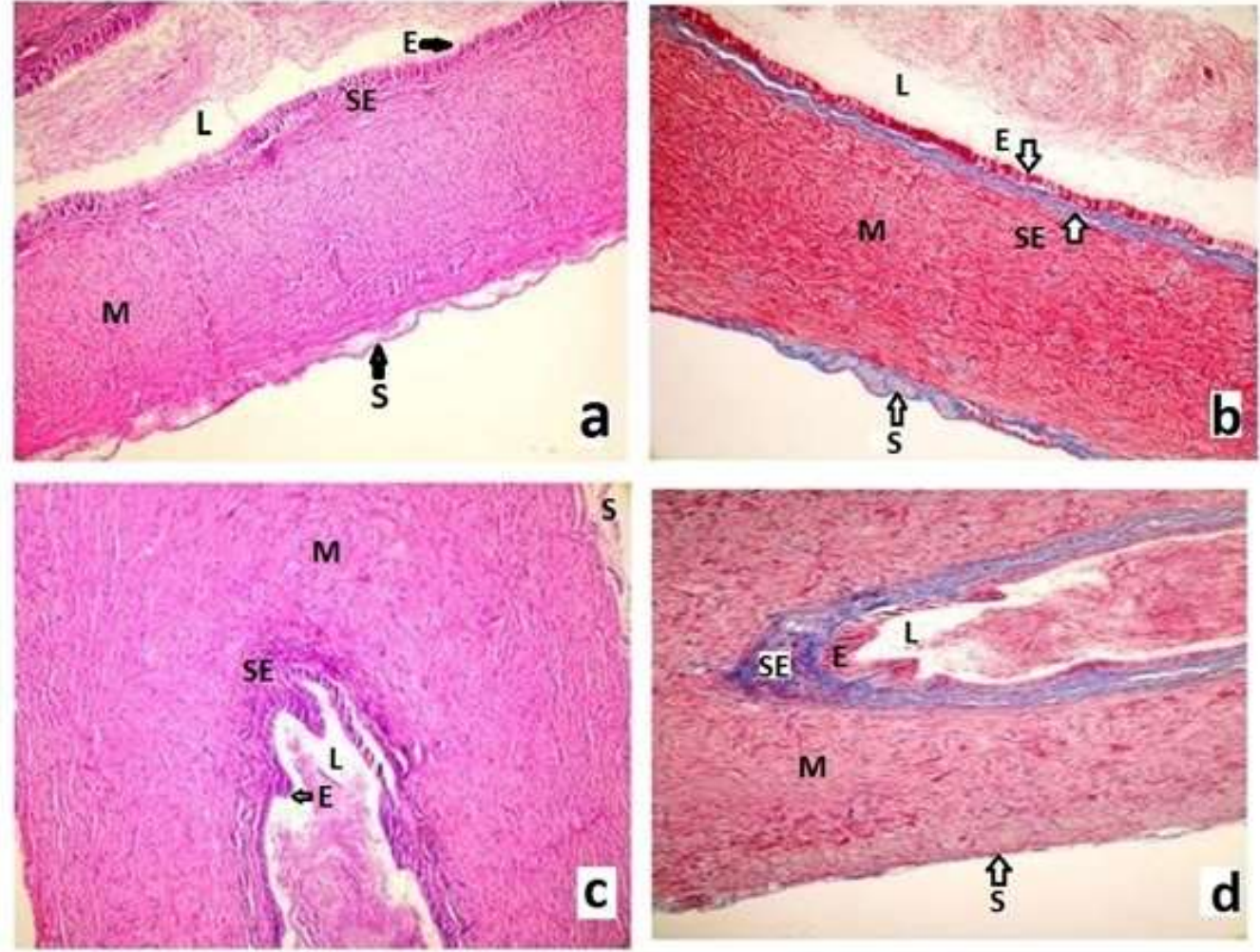

Picture 1: Histopathological appearance of vasdeferens of the groups (H-E stain x100) (a and c); Masson's trichrome stain in both groups, respectively ( $b$ and $d$ ). L, lumen SE, subephitelium M, muscular layer of the vasdeferens $\mathrm{S}$, serosa. Note that there is no difference between groups. 


\section{Discussion}

The consumption of carbohydrate-rich diets has increased considerably in both developed and developing countries. Fructose is one of the important carbohydrate which is not easily metabolized in mammals. The proportional increase in fructose consumption far exceeds the increases in intake of other food groups such as carbonated beverages and other sweetened drinks, baked goods, candies, canned fruits, jams, jellies and dairy products $(11,15)$. The food industry often prefers carbohydrate, particularly fructose to sucrose since they are inexpensive to produce and transport, and fructose mixes well in many foods. In the last four decades, fructose-rich diet consumption has seen a 79.7-fold increase (12).

Several short-term clinical studies have shown that small amounts of fructose have no deleterious effects on metabolism $(13,14)$. Because natural fructose find in relatively small amounts in fruits and vegetables, it is not severe harmful to consume even it be excluded from standart diets (15). High amounts of fructose consumption have been shown to cause hypertriglyceridemia, hyperuricemia and induce insulin resistance. Excessive consumption of fructose may promote obesity, type 2 diabetes mellitus and fatty liver disease (16). In this present study, we showed that a carbohydrate-rich diet which consists of $37-40 \%$ fructose caused marked weight gain $(27.4 \%)$ in the study group whereas it was $9 \%$ in the control group after six weeks period. Because fructose does not require insulin for uptake into the cells, the feeling of satiety has been delayed by the fructose. Natural fructose finds in small amounts in fruits and vegetables, and consumption of these foods, not adversely affect blood-glucose levels. Bantle et al. stated that short-term fructose replacement in the diabetic diet improves glycaemic control (17), whereas other studies found that fructose had deleterious effects on other aspects of metabolism (18).

The negative effects of obesity on erectile and bladder function have been investigated in many clinical studies. Increased intraabdominal pressure due to weight gain which provokes stress on the pelvic floor, impaired neuromuscular function (urge incontinence) and the vascular damage due to systemic oxidative stress origin may be given as pathophysiological mechanisms $(19,20)$. This study was designed to investigate whether carbohydrate-rich diet had negative effects on contractility of the vas deferens. In addition, changes on vas deferens histology and response to dapoxetine were also studied.

Adrenergic nerve fibres predominantly finds in the vas deferens. NA is the main neurotransmitter, whereas vasoactive intestinal polypeptide (VIP), somatostatin and leu enkephalin are the other putative substances (21).
Perivasal ganglionic cells also consist of nonadrenergic, noncholinergic, purinergic nerve fibres (22). In this study, the contractile response of the vas deferens to NA and ATP were investigated. Similar responses in both the main groups and subgroups support the fact that obesity does not contribute to vas deferens dysfunctions. In 2013, Mosli et al. reported that Basal Mass Index (BMI) increases were associated with sexual disorders. Although premature ejaculation PE was thought to be reasoned by obesity (23), our study showed that different mechanisms might play a role in ejaculation other than those having a vas deferens origin.

According to the literature, numerous disturbances can be encountered in the aetiology of ejaculatory dysfunction including retroperitoneal lymph node dissection, major pelvic surgeries, aortoiliac reconstruction, inguinal herniorrhaphy, multiple sclerosis, transverse myelitis and diabetes (24-31). As previously reported by Risely in 1963, the distribution of contractile cells and sympathetic nerves within the vas deferens are responsible for the rhythmic peristaltic movements in the vas deferens during emission that help the movement of sperm through the epididymis.

Total contractile strength, which can be measured using EFS, represents the release of all transmitters into the neuromuscular synaptic space. Our EFS results showed no differences in the control and study groups. The addition of dapoxetine in some subgroups showed similar responses to EFS (Fig.3). The selective serotonin reuptake inhibitor, dapoxetine, was originally approved for the on-demand treatment of PE (32). For this reason, dapoxetine was administered in an on-demand fashion in the groups prior to sacrification of the rats (33). Studies that have focused on histopathological changes of the vas deferens are extremely rare (34). In the present study, we showed no histopathological or pharmacological changes in the vas deferens due to carbohydrate-rich diet in rats.

The short follow-up period is a limitation of this study. Further studies are required to aid in better understanding the effects of a carbohydrate-rich diet on the vas deferens.

\section{Conclusion}

In conclusion, although the carbohydrate-rich diet caused weight gain over a short period of time, pharmacological and histological properties remained stable and dapoxetine had no effect on the contractility of the vas deferens. Even though carbohydrate-rich diet have no negative pharmacological or histological effects on the vas deferens, it should be kept in mind that other parts of the male genital tract may have been negatively affected. 
Conflict of Interest: The authors declare no potential conflicts of interest with respect to the research, authorship, and/or publication of this article.

Ethical issues: All Authors declare that Originality of research/article etc... and ethical approval of research, and responsibilities of research against local ethics commission are under the Authors responsibilities. The study was completed due to defined rules by the Local Ethics Commission guidelines and audits.

Acknowledgement: Author contributions??

\section{Reference}

1. Wang YC, Pamplin J, Long MW, Ward ZJ, Gortmaker SL, Andreyeva T. Severe Obesity In Adults Cost State Medicaid Programs Nearly \$8 Billion In 2013. Health Aff (Millwood). 2015 Nov 1;34(11):1923-31. doi $10.1377 /$ hlthaff.2015.0633

2. Llewellyn A, Simmonds M, Owen CG, Woolacott N Childhood obesity as a predictorof morbidity in adulthood: a systematic review and meta-analysis. ObesRev. 2015 Oct 6. doi: $10.1111 /$ obr.12316

3. Rowland DL, et al. The psychological burden of premature ejaculation. J Urol 2007;177(3):1065-70.

4. Porst H, Montorsi F, Rosen RC, Gaynor L, Grupe S Alexander J. The premature ejaculation prevalence andattitutes (PEPA) survey: Prevalence, comorbidities, and professional help-seeking. EurUrol 2007;51:816-823.

5. Mauro G, Vincenzo F, Arcangelo S, Giovanni C, Sergio S, Shahrokh FS, Mario M, Filiberto Z, Marco C and Giacomo N. Impact of Medical Treatments for Male Lower Urinary Tract Symptoms Due to Benign Prostatic Hyperplasia on Ejaculatory Function: A SystematicReview and MetaAnalysis. 2014 June 11;6:1554-1566.

6. Shamloul R, el-Nashaar A. Chronic prostatitis in premature ejaculation: a cohort study in 153 men. J Sex Med. 2006, $3: 150-154$

7. Laumann EO, et al. Sexual dysfunction in the United States: prevalence and predictors. JAMA 1999 281(6):537-44

8. Ferguson DR, Kennedy I, Burton TJ. ATP is released from rabbit urinary bladder epithelial cells by hydrostatic pressure changes - a possible sensory mechanism? J Physiol. 1997;505:503-511.

9. Driessen B, von K, I, Starke K. Pl-purinoceptor-mediated modulation of neural noradrenaline and ATP release in guinea-pig vas deferens. Naunyn Schmiedebergs Arch Pharmacol 1994;350:42-48.

10. Fukumitsu A, Takano Y, Iki A, Honda K, Saito R Katsuragi T, Kamiya H. Endogenous ATP released by electrical field stimulation causes contraction via $\mathrm{P} 2 \mathrm{X}$ and P2Y purinoceptors in the isolated tail artery of rats. Jpn J Pharmacol. 1999;81:375-380.

11. Salas-Salvadó J, Bulló M, Pérez-Heras A, Ros E. Dietary fibre, nuts and cardiovascular diseases. British Journal of Nutrition. 2006 Nov 1;96(S2):S45-51.

12. Corn Refiners Association. Report on HFCS Consumption Washington, 2013

13. Crapo PA, Kolterman OG, Olefsky JM. Effects of ora fructose in normal, diabetic, and impaired glucose tolerance subjects. Diabetes Care. 1980;3:575-582.
14. Hassinger W, Gaberle E, Schultz G, et al. Blood glucose levels and insulin requirement after fructose as sweetener in diabetic diet. Diabetologia1980;19:281

15. Gaby AR. Alternative Medicine Review 2005;10(4):294306.

16. Elliott SS, Keim NL, Stern JS, et al. Fructose, weight gain, and the insulin resistance syndrome. Am J Clin Nutr 2002; 76:911-922.

17. Bantle JP, Laine DC, Thomas JW. Metabolic effects of dietary fructose and sucrose in types I and II diabetic subjects. JAMA 1986;256:3241-3246.

18. Kawasaki T, Ogata N, Akanuma H, et al. Postprandial plasma fructose level is associated with retinopathy in patients with type 2 diabetes. Metabolism 2004;53:583588 .

19. Cummings JM, Rodning CB. Urinary stress incontinence among obese women: review of pathophysiology therapy. Int Urogynecol J Pelvic Floor Dysfunct 2000;11:41-4.

20. Yoshida M, Yamaguchi O. Detrusor Underactivity: The Current Concept of the Pathophysiology. Low Urin Tract Symptoms. 2014;6(3):131-7. doi: 10.1111/luts.12070.

21. Medina P, Segarra G, Mauricio MD, et al. Role of $\mathrm{Ca}(2+)$ activated $\mathrm{K}(+)$ channels and $\mathrm{Na}(+), \mathrm{K}(+)$-ATPase in prostaglandin $\mathrm{E}(1)$ - and $\mathrm{E}(2)$ - induced inhibition of the adrenergic response in human vas deferens. Biochem Pharmacol 2011; 82(1):65-71.

22. Burnstock G, Verkhratsky A. Vasdeferens-a model used to establish sympathetic cotransmission. Trends Pharmacol Sci 2010;31(3):131-9 PubMed PMID: 20074819.

23. Saad F, Gooren LJ. The role of testosterone in the etiology and treatment of obesity, the metabolic syndrome, and diabetes mellitus type 2. Journal of obesity. 2010 Aug $10 ; 2011$.

24. Basiri A, Ghaed MA, Simforoosh N, et al. Is modified retroperitoneal lymph node dissection a live for clinical stage I non-seminomatous germ cell testicular tumor Urol J. $2013 ; 10(2): 873-7$.

25. Nishizawa $\mathrm{Y}$, Ito $\mathrm{M}$, Saito $\mathrm{N}$, et al. Male sexual dysfunction after rectal cancer surgery. Int $\mathrm{J}$ Colorectal Dis 2011;26(12):1541-8.

26. May AG, DeWeese JA, Rob CG. Changes in sexual function following operation on the abdominal aorta. Surgery 1969;65(1):41-7.

27. Aasvang EK, Kehlet H. Post herniotomy dysejaculation: successful treatment with mesh removal and nerve transection. Hernia 2008;12(6):645-7.

28. Orasanu B, Frasure H, Wyman A, et al. Sexual dysfunction in patients with multiple sclerosis. Mult Scler Relat Disord 2013;2:117-23.

29. Scott TF, Frohman EM, De Seze J, et al. Evidence-based guideline: clinical evaluation and treatment of transverse myelitis: Report of the Therapeutics and Technology Assessment Subcommittee of the American Academy of Neurology. Neurology 2011;77(24):2128-34.

30. Kamenov ZA, Traykov LD. Diabetic autonomic neuropathy. Adv Exp Med Biol 2012;771:176-9.

31. Brown DJ, Hill ST, Baker HW. Male fertility and sexual function after spinal cordinjury. Prog Brain Res 2006;152:427-39. 
32. Carson C, Gunn, K. Premature ejaculation: definition andprevalence. Int J Impot Res 18 Suppl 1, S5-13.

33. De Hong $\mathrm{C}$, Ren LL, Yu H, Qiang W. The role of dapoxetine hydrochloride on-demand for the treatment of men with premature ejaculation. Scientific reports. 2014 Dec 1;4:7269.
34.

Maciel LC, Glina S, Palma PC, Costa NF, Netto NR. Histopathological alterations of the vas deferens in rats exposed to polypropylene mesh. BJU international. 2007 Jul 1;100(1):187-90.

Copyright (C) 2016 The Author(s); This is an open-access article distributed under the terms of the Creative Commons Attribution License (http://creativecommons.org/licenses/by/4.0), which permits unrestricted use, distribution, and reproduction in any medium, provided the original work is properly cited. All Rights reserved by international journal of Medical Science and Discovery. 